\title{
EL TRABAJO EXTERNO EN LA INDUSTRIA JUGUETERA DE LA FOIA DE CASTALLA (ALICANTE)*
}

\author{
José Ramón Valero Escandell
}

\section{RESUMEN}

La industria juguetera de la Foia de Castalla — comarca interior alicantina - mantiene fuertes vínculos con empresas suministradoras de materias, industrias auxiliares, talleres especializados en procesos de fabricación, empresas de servicios e incluso trabajadores autónomos que realizan las labores menos mecanizadas, a veces a muchos kilómetros de distancia. Este artículo estudia el área de influencia de esta industria juguetera y analiza las razones explicativas y la evolución de las relaciones establecidas, utilizando básicamente encuestas y entrevistas a los agentes económicos implicados.

Palabras clave: industria juguetera, Foia de Castalla, industria auxiliar, economía irregular, trabajo femenino.

\section{RÉSUMÉ}

L'industrie du jouet dans la Foia de Castalla (région intérieure de la province d'Alicante) maintient des liens très étroits avec des entreprises qui fournissent la matière, des industries auxiliaires, des ateliers spécialisés dans les processus de fabrication, des entreprises de services et même avec des ouvriers autonomes qui réalisent les travaux moins mécanisés, souvent à plusieurs kilomètres de distance.

Cet article étudie la zone d'influence de cette industrie du jouet et analyse les motifs explicatifs ainsi que l'évolution des relations établies en utilisant principalement des enquêtes et des interviews auprès des agents économiques impliqués.

Mots fondamentaux: industrie du jouet, Foia de Castalla, industrie auxiliaire, économie irrégulière, travail féminin.

Mucho se ha escrito y cuantificado sobre la producción y ventas de la industria juguetera, tanto del conjunto de la juguetería española como - menos - de la establecida en la comarca de la Foia de Castalla, principal espacio de fabricación en nuestro país. Conoce-

* Investigación realizada dentro del Proyecto G.V. 2.401/94. 
mos la evolución de la producción a lo largo del tiempo y en función del tamaño de las empresas y la distribución de las ventas respecto a todo tipo de factores (exportación y venta en el mercado nacional, principales países de destino, estacionalidad, tipo de establecimiento); también existe información suficiente sobre el empleo directo en el sector o sobre las inversiones de capital a lo largo de las últimas décadas. En suma, conocemos bastante aproximadamente la estructura de la industria, al menos en aquello directamente relacionado con ella. En un número anterior de esta misma revista expusimos un estudio bastante actualizado de esta industria, al que nos remitimos para conocer los rasgos generales de la misma (VALERO, 1998).

Por el contrario, existe muy poca información — dispersa y fragmentaria, ademássobre las relaciones que las fábricas jugueteras mantienen con otras industrias y sectores económicos más o menos complementarios, con las que establece lo que podríamos definir como «el área de influencia del sector», que se extiende en un espacio geográfico difuso, con relaciones muy intensas respecto al resto de la industria comarcal, pero mucho más diluidas conforme se incrementa la distancia respecto a esta zona; no obstante, en algunos casos estas relaciones pueden ser particularmente notables con algunas áreas rurales muy concretas, como comprobaremos al hablar de la confección en las industrias muñequeras.

En este artículo trataremos de analizar dicha influencia estudiando los proveedores, los talleres dedicados a actividades auxiliares o a determinadas tareas especializadas dentro del proceso de fabricación del juguete, y las empresas a las que se acude en demanda de todo tipo de servicios. Para ello, además de los datos estadísticos disponibles (algunos gracias a estudios vinculados a la propia patronal juguetera), hemos recurrido a buen número de encuestas y entrevistas ${ }^{1}$, tanto a empresas del sector como a talleres auxiliares e incluso a trabajadoras y distribuidores residentes en alguna de las poblaciones donde se siguen realizando trabajos domiciliarios.

\section{El incremento del trabajo externo en la industria juguetera}

La información más completa que poseemos al respecto (KPMG, 1992), aunque con datos de 1989, evalúa la producción que las fábricas jugueteras españolas realizan externamente en torno al 33,6\% del total, lo que vendría a suponer - en condiciones teóricas de similar productividad - un empleo equivalente a 3.775 trabajadores. Según dicho estudio, la externalización era superior en las fábricas muy pequeñas (el 49,7\% de su trabajo total) que en las empresas grandes (el 29,9\%) y medianas (el 23,3\%). Dado que en la zona de la Foia de Castalla predominaban las empresas de mediano tamaño, podemos presuponer que el porcentaje era, pues, algo inferior a la media nacional, pero en todo caso superaría claramente la cuarta parte de la producción total. Un estudio mucho más reciente (SÁEZ, 1997), realizado también mediante encuesta, calculaba un $25 \%$ de promedio de externalización productiva para las empresas de la Foia de Castalla. Este dato supondría el mantenimiento porcentual del trabajo que las empresas jugueteras subcontratan fuera de sus propias instalaciones productivas.

1 Las empresas consultadas fueron «Coloma y Pastor», «Gozán», «Industrial Juguetera», «Juguetes Chicos», «Juguetes Feber», «Juguetes Mira», «Juguetes Vercor», «Juguetes y Herrajes Joal», «Moltó y Cía» y «Talleres La Paz», en Ibi; «D’Azúcar», «Industrias Falca» y «Famosa», en Onil»; «Dalber» y «Muñecas Arias», en Castalla y «Jesmar» en Biar. Además, se ha obtenido información sobre aspectos puntuales de empresas ya desaparecidas, como «Berjusa» de Onil y «Guillem y Vicedo» de Ibi. Asimismo, se ha recurrido a entrevistas con trabajadoras y repartidores vecinos o distribuidores en las provincias de Almería, Granada, Murcia, Albacete, Toledo o Ciudad Real, ocho en total. 
Sin tratar de desmentir la información anterior, creemos conveniente razonar que ese 25\% representa el umbral mínimo de externalización realmente existente, pues el proceso de descentralización productiva y subcontratación está más firmemente asentado que nunca y lleva camino de incrementar su importancia estructural en el sector. En primer lugar, entre 1989 y 1997 se produjo un aumento notable de la producción juguetera de la zona, si atendemos ${ }^{2}$ a las declaraciones tan positivas que sobre producción, reactivación del consumo y exportación se han realizado en estos últimos meses, de acuerdo con la etapa de bonanza económica vivida en 1996 y 1997; sin embargo, este incremento se ha producido en medio de una fuerte destrucción de empleo en las empresas jugueteras de la zona que, sólo en parte, ha sido compensado con una mejora de la productividad.

En segundo lugar, parece generalizarse la tendencia a subcontratar externamente alguno de los procesos de fabricación necesarios para la producción del juguete. El trabajo de Sáez antes citado hablaba de que «un 70\% de los empresarios encuestados afirmaba haber optado por externalizar una o más etapas de su proceso productivo». Al mismo tiempo, las industrias susceptibles de trabajar, esencial o parcialmente, como auxiliares de la industria juguetera no sólo se han desarrollado en estos años en las poblaciones de la Foia sino que en algunos casos han alcanzado una naturaleza que supera claramente el ámbito de la juguetería: en Ibi, según un censo empresarial de 1996 facilitado por Aproibi (la Oficina de Promoción Económica local), seguían funcionando 28 industrias jugueteras pero ya eran 55 los talleres de matricería y moldes y 70 las empresas de inyección de plástico y otros tipos de talleres auxiliares. El volumen alcanzado indica que en modo alguno pueden ser considerados sólo como instalaciones auxiliares de la industria juguetera, pues sus actividades van dirigidas ya a multitud de sectores productivos, pero es evidente que este crecimiento ha sido sostenido en gran medida por las demandas de la juguetería y, al mismo tiempo, han posibilitado que las fábricas de juguetes hayan podido derivar sin dificultad aquellas tareas que les resultaba costoso o molesto producir en sus propias instalaciones. Finalmente, pese a los esfuerzos realizados, parece evidente que la estacionalidad de la demanda de juguetes continúa siendo todavía un problema insoslayable, dada la costumbre de vincular buena parte de las compras a las fiestas de Navidad y Reyes; ante ello, la posibilidad de disponer de una capacidad productiva externa, susceptible de ser utilizada en los momentos de mayor agobio, incentiva todavía más la externalización de buena parte del proceso productivo.

En el otro plato de la balanza habría que situar el descenso de buena parte del trabajo domiciliario, al menos en la forma en que se realizaba tradicionalmente en esta comarca. Aunque todavía resulta fácil encontrar trabajadores domiciliarios, casi siempre mujeres, en muchos barrios de cualquiera de las poblaciones comarcales, es cierto que —al menos desde la implantación del I.V.A., que ha dificultado el funcionamiento clásico de estas labores- parece tender a remitir, por toda una serie de factores legales, de calidad, de organización productiva o de alternativas laborales, aunque diferenciando municipios, sectores de población y coyunturas económicas. No obstante, algunas de estas formas tradicionales y degradadas de externalización productiva siguen siendo una realidad suficientemente importante en algunas labores (como la confección de vestidos para muñeca, que estudiaremos con detalle en otro apartado) e incluso en ocasiones se ha reencarnado bajo apariencia de legalidad.

A menudo, cuando nos referimos a la externalización, al trabajo indirecto en la industria, no sólo en la juguetera, parece que estamos citando únicamente las fases del proceso

2 A la hora de escribir este artículo todavía no poseemos los datos definitivos de la producción del sector juguetero durante el año 1997. 
productivo propiamente dicho; en realidad, aludimos a todas las funciones que tradicionalmente desempeñaba una empresa industrial de cierta entidad y que ahora se contratan fuera de ella, es decir, a una serie cada vez mayor y más compleja de servicios a las empresas. También en este aspecto cualquier sector industrial externaliza buena parte de sus antiguas funciones (y de las que han adquirido una importancia reciente), ejerciendo con ello una influencia económica sobre un espacio más o menos dilatado, estableciendo relaciones más o menos intensas pero que siempre interesa conocer. Pero, aún antes, el aprovisionamiento de materias primas ha establecido ya unas relaciones similares, por lo general mucho más dilatadas y difusas espacialmente, pero que también son parte de la influencia económica y laboral de una industria.

\section{Aprovisionamiento de materias primas y útiles}

La mayoría de materias primas necesarias para la industria proceden de zonas bien alejadas de la propia comarca, aunque sólo algunas empresas se abastecen de ellas en otros lugares. Tal vez el plástico, el principal componente actual de los juguetes, pueda servir como ejemplo: mientras las mayores empresas pueden llegar a algún tipo de acuerdo con grandes multinacionales del sector a través de sus delegaciones en España, las medianas suelen negociar con los representantes de dichas delegaciones y las fábricas modestas recurren a algún distribuidor o almacenista local; el hecho de que muchas empresas jugueteras no se abastezcan directamente de plástico sino que reciban ya las piezas fabricadas por los talleres de inyección no varía la situación, porque también ellos suelen operar de la manera antes descrita. Por lo general, es Cataluña (en concreto, las multinacionales fabricantes o distribuidoras allí establecidas) quien suministra la mayoría del producto necesario.

También Cataluña es la principal suministradora de productos textiles, utilizados principalmente por las fábricas de muñecas y de cochecitos, aunque en este caso existe también una notable competencia de empresas valencianas, básicamente de municipios bastante próximos (Alcoy, Onteniente e incluso alguna fábrica de la zona juguetera). En este caso, mientras la gran empresa posee entidad suficiente para diseñar sus propios tejidos, las más modestas deben acudir al clásico viajante e incluso a los almacenistas locales.

Otras materias primas requeridas a grandes empresas son la pintura, los metales o las baterías y motores. La pintura suele proceder de factorías — radicadas en España o nodependientes de los grandes conglomerados químicos multinacionales, aunque la forma de aprovisionamiento suele ser similar a la empleada para el plástico. Los metales —hierro, acero y zamac, una aleación del cinc - son recibidos en la comarca desde las grandes empresas metalúrgicas de la cornisa cantábrica, aunque desde la pertenencia española a la Unión Europea se han diversificado los suministros; por lo general, los productos férreos no suelen llegar directamente a las empresas jugueteras sino que estas adquieren productos concretos, como el tubo, el fleje o los muelles, que en un porcentaje altísimo adquieren a industrias de la propia comarca, lo que con los años ha generado otro importante sector industrial, capaz de suministrar productos a sectores tecnológicamente tan avanzados como las industrias automovilísticas; los aceros más sofisticados, aquellos empleados para la matricería, proceden de Suecia a través de importadores en España. Las baterías, motores y cargadores son un componente esencial para las empresas dedicadas a la fabricación de motocicletas y coches conducidos por los propios niños, es decir, por lo general, las mayores empresas de la comarca y las más tecnificadas; aunque pueda pasar desapercibido, se trata de un componente básico, hasta el punto de que una directiva de «Feber», en entrevista realizada en agosto de 1997, afirmaba que, hasta ese mes, sus compras por esa 
partida ascendían ya a 235 millones de pesetas; se adquirían a una empresa inglesa, aunque eran de procedencia china.

El cartón, utilizado tanto para algunos juegos como para las cajas de juguetes y los envases externos, es casi totalmente de procedencia valenciana; aunque una parte nada despreciable procede de la propia industria ibense, son mayoría las empresas que recurren a fabricantes de Elche, Xàtiva u Onteniente. En cuanto a otros envoltorios, como los de poliuretano expandido, su procedencia es mayoritariamente comarcal.

Algunos suministros muy específicos de la juguetería o muy utilizados por la misma son producidos casi exclusivamente en la propia comarca y forman parte de la infraestructura que otorga a la Foia de Castalla ventaja comparativa respecto a otras zonas del Estado a la hora de ubicar una nueva fábrica juguetera. Entre estos suministros podemos citar algunos tan concretos como los ojos o el pelo de muñeca (fabricados en Onil) o la impresión de adhesivas; en este último caso, las empresas de Ibi no sólo fueron capaces de sustituir prácticamente todo el material llegado anteriormente de Cataluña, sino que han conseguido diversificar su clientela a otros muchos sectores (por ejemplo, una empresa fabrica adhesivas capaces de sustituir la pintura decorativa de un casco de moto).

Sobre compras de maquinaria, aunque pocas empresas consultadas afirmaron haber adquirido recientemente nuevas máquinas - en parte, por la tendencia creciente a externalizar parte de la producción- parece retroceder claramente la maquinaria de origen nacional. Hoy parece ser que predominan las adquiridas en Alemania o Italia, aunque todavía es común recurrir a distribuidores establecidos en el área de Barcelona. De cualquier manera, también la comarca es capaz de suministrar ciertos productos, como los hornos de fundición que algunos afirmaron haber encargado en Castalla, o las máquinas de soplado de plástico fabricadas en Ibi.

\section{La demanda de servicios a las empresas}

Existe una serie de servicios, como el transporte, que todas las industrias jugueteras han encargado tradicionalmente a agencias establecidas en la propia comarca y aún en el mismo municipio. Otros servicios más sofisticados, como la publicidad, tampoco han sido asumidos por las empresas sino que se han contratado con agencias de fuera de la comarca. Hoy, las empresas requieren servicios cada vez más complejos (asistencia tecnológica, mantenimiento, asesoramientos) y muchas veces tratan de resolver externamente muchos de los cometidos que tradicionalmente asumían como propios (diseño, comercialización, incluso mano de obra). En nuestras encuestas y entrevistas tratamos de medir la demanda de servicios en relación con el diseño, la comercialización, el asesoramiento, la publicidad y el recurso a las empresas de trabajo temporal.

En cuanto al diseño, las fábricas jugueteras de la comarca mantienen políticas bien diferenciadas en función de su propia capacidad económica y de la tradición seguida por cada empresa. Existen firmas que cuentan con una empresa de diseño integrada en su propio grupo de empresas — caso de «Creatividad y Diseño», perteneciente al Grupo Feber-y otras que simplemente son capaces de adaptar ideas más o menos generales de juguetes clásicos y recurren a personal especializado en la propia comarca. Aunque la originalidad es bastante limitada en la mayoría de productos, que suelen seguir la tendencia general a escala mundial, dentro de la gama de juegos y juguetes que la empresa fabrica, las empresas afirman dedicar cada vez una mayor atención a I+D, tratando de singularizar su propio producto y mejorar diseños y calidades; ello les lleva a valorar todas las ideas recibidas, vengan de donde vengan, aunque esencialmente el trabajo de diseño suele centrarse en la propia comarca. Alguna gran empresa afirma que contacta con varios 
gabinetes de diseño; otras empresas medianas declaran contar con diseñadores de algunas grandes ciudades que, de cuando en cuando, presentan algún modelo de nuevos juguetes; son, por lo general, gentes de Madrid, Barcelona o Valencia y sólo una empresa afirmaba contar con un diseñador extranjero, un alemán que solía colaborar en el diseño de algunas piezas. Algún empresario afirmaba que muchos diseñadores ajenos al sector no son capaces de traducir sus ideas a las posibilidades reales de fabricación del producto, por lo que muchas veces la idea, teóricamente muy original, se enfrenta a dificultades técnicas insalvables o a un proceso de fabricación económicamente inviable. Por ello, el grueso del diseño, como indicábamos antes, se concentra en la propia comarca, incluso en el interior de las propias empresas; las mayores cuentan con sus propios gabinetes o empresas de diseño, que se ocupan desde la idea general a los mínimos detalles — hasta los tipos de tejido y la estampación, en algún caso- y sólo puntualmente recurren a técnicos ajenos a la plantilla. Las medianas, que sí recurren más frecuentemente al trabajo externo, suelen ofrecer una idea general del producto deseado y sus colaboradores se encargan de buscar posibles soluciones. Por lo general, de la comarca son la mayoría de los dibujantes a los que se recurre, la práctica totalidad de los escultores dedicados a la creación de modelos de muñecos y buena parte de los diseñadores gráficos (tanto de los juguetes propiamente dichos como de las cajas en que se presentan).

La comercialización es muy diferente tanto entre las distintas empresas como en lo que respecta al mercado español y a la exportación. Las grandes firmas han creado empresas diferenciadas integradas en su propio grupo para afrontar la comercialización total o parcial de sus productos; así, por ejemplo, «Famosa Comercial». Otras, de distinto tamaño, se agrupan en grupos comerciales creados hace décadas al amparo, en buena medida, de las desgravaciones fiscales a la exportación o simplemente como manera más eficaz de disponer de una distribución internacional que no podían haber conseguido por sí solas; pero, mientras alguna empresa distribuye toda su producción a través de estos grupos, otras sólo recurren a ellos para la exportación a otros países. Por lo general, para el mercado interior la práctica totalidad de las empresas recurre a los representantes tradicionales (los viajantes), que en ocasiones mantienen relaciones casi familiares con la empresa; mientras algunas firmas cuentan casi exclusivamente con representantes establecidos en las ciudades principales de cada una de las zonas en que dividen su mercado interno (Barcelona, Madrid, Sevilla...), otras se decantan más por personal de la propia Foia de Castalla, que puede estar mucho más en contacto con la empresa, y unas terceras se encuentran en una situación intermedia; la mayoría de estos representantes no suelen ser exclusivistas de una empresa, sino que ofertan productos de diferentes firmas, aunque casi siempre tratando de compaginar aquellas que se dedican a gamas diferenciadas (por ejemplo, muñecas, triciclos y juegos de mesa). Recientemente, con el desarrollo de los hipermercados y de las tiendas especializadas, algunas fábricas han optado por dedicar una persona de la propia empresa, generalmente el jefe de ventas, a la atención de estos grandes clientes. En casos excepcionales, la estructura comercial está limitada por la propia forma de venta de la empresa, como una fábrica de muñecas que distribuye su producción en unas pocas tiendas selectas vinculadas a la propiedad del negocio o una empresa que dedica buena parte de su fabricación a producir miniaturas para grandes casas automovilísticas.

En cuanto al asesoramiento, tanto jurídico como laboral o fiscal, sólo la mayor de las empresas posee la envergadura suficiente para contar con departamento propio; el resto tiende a encomendarlo a gabinetes externos. Salvo una empresa que afirmaba recurrir a un despacho de abogados en la ciudad de Valencia para los asuntos más complejos, el resto acude a profesionales de la propia provincia, normalmente establecidos en Ibi o en Alicante, aunque en algún caso estaban asesorados desde Elche, Onil o Villena. Por lo general, las 
empresas más antiguas, aquellas fundadas antes de mediados de los años sesenta, son las más proclives a acudir a profesionales de fuera de la Foia de Castalla, porque en aquella época los municipios de la zona apenas contaban con personal técnico para asumir estas funciones; con el paso del tiempo, las relaciones con esos asesores han ido haciéndose cada vez más estrechas y creando un conocimiento mutuo difícil de sustituir; por eso, las empresas que se encontraban en este caso afirmaban que, aunque hoy hubiesen optado por acudir a profesionales de la comarca, no encuentran razones para cambiar. Aproximadamente la mitad de las empresas afirmaban encomendar sus asuntos fiscales y laborales al mismo despacho, mientras que el resto acudía a profesionales diferentes para cada cosa; en esta última situación, era común acudir a asesorías del propio municipio para los asuntos más habituales y a abogados de ciudades mayores para consultas y trámites más complicados.

A la hora de analizar la influencia de la industria juguetera en el sector de la publicidad, habría que distinguir los catálogos y anuncios impresos de las campañas publicitarias de carácter audiovisual, sólo al alcance de unas pocas marcas. Las dos principales empresas jugueteras de la zona, «Feber»y «Famosa», cuentan con departamentos internos de comunicación (en realidad, empresas del grupo, «Creadisa» y «Onilco», respectivamente), capaces de diseñar las líneas maestras tanto de sus catálogos como de sus campañas publicitarias, que en un caso se vuelcan en la publicidad televisiva y en el otro en la publicidad directa en los catálogos de las grandes empresas de distribución comercial; aún así, ambas tienen que recurrir a imprentas externas a la comarca o a agencias de publicidad de grandes ciudades. Por lo general, el resto de empresas realizan sus catálogos en empresas especializadas de Valencia o Alicante, que suelen entregar el producto completamente listo para repartir, o en su propia empresa con ayuda de algún diseñador gráfico de la zona, recurriendo posteriormente a alguna imprenta de la comarca o de Alicante. Las empresas que realizan anuncios televisivos acuden a agencias de publicidad establecidas en Valencia o Madrid, casi siempre manteniendo una fidelidad de varios años; luego, estas firmas contratan con las grandes cadenas televisivas españolas campañas publicitarias, especialmente intensas durante las semanas previas a las fiestas navideñas; se trata de uno de los grandes costes que deben afrontar las principales empresas jugueteras y es, junto con la adquisición de las materias primas principales, el gasto que menos revierte en la propia comarca.

Escasa incidencia posee todavía en esta industria la contratación de mano de obra más o menos ocasional a través de las E.T.T. (empresas de trabajo temporal). Alguna empresa llegó a utilizar esta mano de obra durante breve tiempo, para renunciar a ella una vez valorada la experiencia. Sólo una de las mayores empresas parece recurrir a esta práctica en una de sus cadenas de montaje, a través de una empresa establecida en Alicante, aunque casi siempre se trata de multinacionales. Casi todos los entrevistados afirmaban que nunca se habían planteado esta posibilidad porque, cuando necesitaban mano de obra, recurrían a la oficina del I.N.E.M. porque entendían que entre los parados de la comarca había gente bien preparada para lo que ellos necesitaban. Pero la situación es suficientemente variada; por ejemplo, en alguna de las empresas más antiguas, que proceden de situaciones de mayor empleo en las secciones productivas de la propia fábrica y que tienen dificultades para desprenderse de los empleados fijos y ya entrados en años, la situación sería absurda porque tienen exceso de mano de obra estable. Algunas fábricas recurrieron a esta práctica y desistieron por motivos diferentes; en un caso, afirmaban que resultaban caras y no se trataba de trabajadores especializados, sino gentes a las que les costaba adaptarse a su puesto; otra empresa recurrió a ellas ante problemas con sus trabajadores (muchos de ellos con altos incentivos de antigüedad y otras mejoras), que llevó a la decisión de no contratar a ningún nuevo empleado, aunque finalmente se llegó a una solución pactada, que pasaba 
por condiciones laborales diferentes para los obreros de nuevo ingreso y la renuncia de la empresa a contratar con las E.T.T. Alguna de estas E.T.T. cuentan con delegación en Ibi y Onil, aunque suele ser a través de empresas de servicios dedicadas esencialmente a otros menesteres.

\section{El desarrollo de las empresas de procesos industriales}

La tendencia a la descentralización productiva y la subcontratación parece tender a afianzarse cada vez más en la industria juguetera de la Foia de Castalla y, consiguientemente, dado el alto porcentaje que representa en los productos realmente fabricados en nuestro país, en la de todo el Estado. Un estudio de 1995 encargado por la propia organización patronal entendía que la subcontratación (suponemos que este concepto incluiría tanto la descentralización productiva como la subcontratación estricta) era, junto con los gastos de promoción, la partida que mas tendería a aumentar en la cuenta de resultados (AEFJ, 1995); además, dicho estudio planteaba que una de las alternativas de las «pymes» era la de subcontratación:

«una estrategia de subordinación parcial o total de una empresa a otra para la que desarrolla una parte sustacial en alguna de las actividades de la cadena de valor de estas (producción, logística, etc.). Aquellas empresas sin una posición en el mercado consolidada y sin los recursos necesarios para conseguirla deberían orientarse hacia una estrategia de este tipo.» (Fase II. Conclusiones. p. 25).

La tendencia a la descentralización está fundada en una mayor racionalización del proceso productivo, tratando las empresas de concentrar su actividad en aquellos aspectos que les aporten mayor valor añadido o en los que sean claramente competitivas, intentando trasladar el resto de funciones a empresas especializadas. Esta tendencia se ha visto favorecida por el intenso desarrollo de una infraestructura adecuada en las distintas poblaciones de la comarca, singularmente en Ibi, que ha permitido externalizar parte de la producción en condiciones singularmente ventajosas, porque se ha podido contar con empresas excepcionalmente próximas, competitivas y competidoras, que han surgido a partir de la propia industria juguetera.

Las principales empresas de la Foia de Castalla han racionalizado nítidamente esta ventaja de externalizar uno o varios procesos productivos y son conscientes de que esta posibilidad constituye una de sus principales fortalezas, ventajas comparativas respecto a otras zonas productoras. En casi todas las entrevistas en que se abordó el tema, los informantes sustentaron opiniones positivas respecto a esta situación: piensan que son empresas suficientemente tecnificadas, cercanas y controlables (en ocasiones se encuentran en el mismo polígono industrial que la empresa cliente e incluso en un caso se sitúa en la propia factoría, alquilando una de las naves), que trabajan a precios ventajosamente competitivos, a veces más baratos de lo que resulta producirlos internamente, aunque se disponga de los medios para ello; además, posibilitan conocer exactamente el coste de fabricación, permiten despreocuparse del absentismo laboral y no obligan a disponer durante todo el año de una capacidad productiva que sólo sería utilizada a pleno rendimiento durante un par de meses. Más aún, algún informante perspicaz afirmaba que el hecho de que estas empresas se vean obligadas a buscar alternativas al juguete en otros sectores industriales, les permite actualizarse tecnológicamente con gran rapidez, lo que repercute también en los niveles de calidad y precio de los productos jugueteros. Por ello, las firmas 
han comprendido que deben propiciar una fidelización de relaciones con los talleres auxiliares, intentando garantizarse una estructura productiva externa que permita afrontar positivamente los momentos de elevada demanda; por eso, en mayor o menor medida, se trata de suministrar pedidos durante todo el año y, aunque todos afirmaban aceptar y estudiar cualquier nueva oferta, se declaraban reacios a sustituir al proveedor estable por una oferta a precios especulativos difícilmente mantenibles durante mucho tiempo. Incluso empresas jugueteras fuertemente ligadas a talleres auxiliares, como «Feber» respecto a «Tratamientos Plásticos» o «Injusa» respecto a «Tyrsa», tratan de diversificar sus colaboradores y de fidelizar la relación con ellos.

En este aspecto de la descentralización productiva, la influencia de la industria juguetera es notable económicamente pero no extensa espacialmente, porque la parte de león de sus demandas se concentra en la propia zona de la Foia de Castalla (y Biar, que para el estudio de la industria juguetera lo consideramos parte de la misma comarca): el $76 \%$ del total de esta externalización es asumido por talleres y fábricas de la Foia, según el estudio de A. Sáez antes citado. A juzgar por las declaraciones de los entrevistados, esta cifra podría considerarse muy moderada. Si bien la descentralización abarca un mayor número de actividades, en este artículo analizamos fundamentalmente la matricería, la inyección y soplado de plásticos, el montaje y el cosido de vestidos para las muñecas.

La fabricación de matricería y moldes es una actividad con larga tradición en Ibi, donde las primeras fábricas siempre trataron de mantenerla en el seno de la empresa: era la mecánica, como se le llamaba tradicionalmente, y mecánicos eran los trabajadores manuales mejor considerados de las empresas. Sólo cuando se produjo en los años cincuenta la diversificación empresarial del sector a partir de las grandes fábricas pioneras, algunas empresas con dificultades para mantener una sección tan costosa se agruparon para poner en marcha talleres vinculados a ellas. Con los años, el número de talleres de matricería ha llegado a ser en la comarca muy superior al de las propias fábricas jugueteras, al tiempo que han tratado de diversificar su clientela.

Aunque aún existen fábricas que se resisten a abandonar la elaboración de una parte fundamental de la matricería necesaria para sus juguetes, también existen muchas que la encargan totalmente a talleres especializados. Lo normal entre las firmas de cierta entidad es que todavía conserven taller propio en el interior de la fábrica pero que encarguen la mayoría de modelos a uno o varios talleres de la comarca; por lo general, dispongan o no de taller propio, cuanto mayor es la empresa, a mayor número de talleres realiza peticiones, llegándose a veces a disponer de más de media docena de proveedores estables. De acuerdo con los informantes entrevistados, son los talleres de Ibi los que satisfacen el grueso de la demanda, seguidos por los de Onil y Castalla, más volcados hacia las peticiones de las empresas muñequeras, aunque cada vez existe una mayor interconexión productiva entre los distintos pueblos. De los entrevistados, sólo una empresa recurría a una industria de Cataluña, aunque únicamente para las piezas de gran tamaño. Durante algún tiempo se contempló la alternativa de fabricar la matricería en Portugal, en industrias con tecnología suficiente y precios competitivos, pero el inconveniente que representaba la distancia acabó haciendo fracasar la experiencia, pues las industrias están acostumbradas a realizar frecuentes pruebas del molde antes de comenzar la fabricación seriada.

En cuanto a la inyección y soplado de plástico, la situación es muy diferente de unas empresas a otras pero ningún informante recurría a industrias ajenas a la propia comarca. Sólo alguna de las empresas pequeñas encargaba todo el proceso fuera de la propia fábrica; por el contrario, quienes producían casi todo por sí mismos eran las firmas más tradicionales con exceso de mano de obra, que en algún caso están incluso en disponibilidad de realizar encargos de otras empresas. Lo normal es una situación intermedia, en la que las 
empresas demandan pequeños encargos a lo largo del año y recurren a las industrias auxiliares en los meses de mayor demanda. También en este caso son las grandes empresas quienes recurren a un mayor número de talleres, siempre de la propia comarca; aunque existe una empresa que encarga trabajos a talleres de Onil, Ibi, Biar y Castalla, lo normal es que las empresas ibenses recurran casi siempre a talleres del propio municipio, mientras que las industrias muñequeras más pequeñas tiendan a encargar sus pedidos a empresas de Castalla y Onil, más vinculadas con aquella actividad.

Recientemente, parece diversificarse la oferta de descentralización productiva de la industria juguetera. Así, además de las empresas de montaje de juguetes o de confección de vestidos (a las que nos referiremos en el siguiente apartado), han aparecido también talleres de pintado o embalaje, en la propia comarca. Sólo algunos procesos muy específicos, como el xerigrafiado en madera de algunos tipos de cunitas y cochecitos, se siguen realizando esencialmente fuera de la comarca, en este ejemplo concreto en un municipio de las cercanías de Valencia, una de las tradicionales zonas productoras del juguete de madera en España.

\section{Montaje de juguetes}

El montaje era realizado tradicionalmente por las propias industrias jugueteras, bien en la propia cadena de montaje, donde empleaban casi exclusivamente personal femenino predominantemente joven, bien mediante reparto domiciliario, casi siempre a mujeres de los mismos municipios de la comarca, que realizaban las tareas sin ningún tipo de contrato laboral, compaginando las labores hogareñas con estos montajes, trabajo en el que a menudo eran asistidas por otros miembros de la propia familia. Ambas formas de producción solían presentar un cierto equilibrio en el seno de la mayoría de empresas, que siempre contaban con trabajadoras legalizadas pero también trataban de externalizar una parte del trabajo, por el ahorro de costes sociales que representaba. El trabajo domiciliario, aunque todavía no ha desaparecido a pesar de que todos los entrevistados afirmaban que no existía en su empresa, sufrió un claro retroceso a partir de la implantación del I.V.A., que obligaba a las trabajadoras a extender facturas justificativas del trabajo realizado o, lo que es lo mismo, les obligaba a darse de alta como trabajadoras autónomas y en el Impuesto de Actividades Económicas; lógicamente, los ingresos percibidos por estas mujeres no les permitían regularizarse laboralmente, lo que para algunas de ellas hubiese supuesto pagar más de lo realmente percibido. Aunque el descenso no se produjo bruscamente, las empresas han ido tratando de ajustarse a la legalidad en este aspecto: sólo la externalización del trabajo a empresas de montaje o a trabajadores autónomos pudo servir como alternativa, pues las empresas eran reacias a generar empleo en cadenas de montaje internas que hubieran incrementado fuertemente tanto los costos como el precio final del producto, restándole competitividad al juguete de la zona. Estas empresas de montaje y estos trabajadores autónomos sí podían emitir facturas de modo absolutamente legal, con lo que las industrias jugueteras tenían completamente resuelto el problema, de igual modo que si adquiriesen plástico o pagasen un anuncio televisivo, sin obligación de preocuparse de lo qué pasaba de puertas afuera de sus instalaciones. El problema subsiste, lógicamente, bien a través de ese trabajador autónomo que factura las tareas realizadas por varios otros, bien a través de alguna empresa de montaje que vuelve a reproducir los problemas anteriores. No obstante, esta tendencia, que ha llevado a la paulatina reducción del montaje en el interior de las fábricas, ha abierto también oportunidades a nuevas empresas organizadas de una forma más eficaz y moderna.

De las empresas consultadas, algunas siguen manteniendo el montaje en el interior de su fábrica (salvo en circunstancias excepcionales), por motivos muy diferentes según los 
casos; así, varias empresas medianas lo hacen por necesidad, dado el alto porcentaje de mano de obra y de personal fijo que todavía mantienen; otras, pequeñas pero dedicadas a productos especializados, dicen hacerlo para mantener un control de calidad riguroso; alguna lo hace porque sus piezas son excesivamente grandes - lo que encarece los traslados- y cuentan con instalaciones tecnológicamente avanzadas. Hoy son mayoritarias las empresas que combinan el montaje interior con la descentralización a empresas de montaje o locales, organizando racionalmente la distribución, bien reservándose las labores últimas y el embalaje para controlar la calidad final, bien externalizando determinados submontajes o modelos. Finalmente, otras firmas ya realizan externamente todo el montaje. Casi todas las empresas realizan el montaje de sus productos en su propio municipio o en los pueblos cercanos, a veces recurriendo a diversos talleres; de todas las entrevistas mantenidas, sólo un informante declaraba realizar una parte del montaje en La Torre de les Massanes; de las observaciones propias a lo largo del trabajo de campo en que se basa buena parte de este artículo, sólo en una ocasión se pudo constatar el rellenado de peluches en una pedanía de un pueblo andaluz; parece que la distribución de piezas de juguetes para ser montadas en poblaciones muy alejadas de la comarca resulta antieconómico, dado el volumen que representa en relación con el tiempo que se tarda para su montaje.

\section{La confección para muñecas: una necesaria reconversión}

El cosido de vestidos de muñeca es un caso diferente al del montaje. Esta es, de todas las actividades vinculadas a la industria juguetera, la que posee una mayor repercusión social entre gentes de ingresos económicos muy modestos y, además, es aquella cuya influencia afecta a un espacio geográfico más extenso. La confección de vestidos, vinculado a la industria muñequera desde sus orígenes, ni estuvo ni está ni probablemente estará realizada mayoritariamente en el interior de las propias fábricas. Sin embargo, la información facilitada por las propias empresas no ha sido ni amplia ni mínimamente detallada; casi todos los entrevistados se limitaron a indicar que ellos pagaban por este servicio unas facturas absolutamente legales. Esta escasa información, precisamente en el tipo de trabajo en el que la industria juguetera ejerce una mayor influencia extracomarcal, obligó a realizar un trabajo de campo mucho más pormenorizado, con observaciones directas y entrevistas a repartidores de cortes, a mujeres dedicadas a estas tareas, a trabajadores de las propias fábricas muñequeras, tanto en la propia Foia de Castalla como en alguna de otras poblaciones donde tiene más incidencia. Hizo falta recurrir a informantes ampliamente conocedores de estas actividades, bien como distribuidores o como trabajadoras; fueron ocho entrevistas, espacialmente significativas y bastante pormenorizadas, con cuyos datos - que consideramos muy fiables, pues en todo momento se ha respetado la confidencialidad y se realizaron en un ambiente distendido, a través de contactos de toda confianza del informante- hemos intentando caracterizar suficientemente el fenómeno.

En principio, la mayoría de empresas sigue realizando internamente el corte de las piezas, aunque ya existen en la comarca talleres dedicados a estas funciones. También cuentan con un número relativamente reducido de trabajadoras dedicadas a la confección de las muestras, de partidas pequeñas, del repaso de las entregas y de alguna urgencia; normalmente, están empleadas durante todo el año, aunque en algún momento pueda incrementarse su número. Sólo alguna empresa dedicada a la muñeca de alta calidad afirmó coser la práctica totalidad de su producción dentro de fábrica; todas las demás dijeron que la confección era una tarea externa a la propia empresa.

Tradicionalmente, el cosido de vestidos de muñeca era una actividad vinculada al empleo domiciliario de mujeres de la zona, mayoritariamente de aquellas que tras el 
casamiento abandonaban su empleo para dedicarse a las tareas de la casa y trataban de encontrar algún tipo de tarea complementaria a su nueva ocupación fundamental, aunque en muchos casos acabase convirtiéndose en un trabajo que ocupaba un número de horas igual o superior a la jornada laboral legal. A estas ocupaciones se dedicaba la mayoría de las mujeres de Onil, de Castalla y de Biar, los tres grandes núcleos de la juguetería provincial, pero también algunas de Ibi, Tibi y de poblaciones próximas a la Foia. Era gente que acudía a diario a las fábricas a entregar la faena realizada y recoger nuevas tareas, o a la que los empleados de la propia fábrica les repartían diariamente las bolsas con los cortes a confeccionar. Pero a lo largo de los años sesenta el desarrollo de la industria llegó a ser tan grande que el trabajo de las mujeres de la zona resultó insuficiente y había que encontrar alternativas que garantizasen la producción.

La solución consistió en incrementar notablemente el área de distribución y dar paso a la figura del repartidor, una persona ajena a la empresa, vecina de algún pueblo de la Foia o de los lugares en que se realizaba la confección, que conocía perfectamente un territorio en el que había suficiente número de mujeres dispuestas a trabajar para las industrias jugueteras; casi siempre, se trataba de zonas rurales en las que el trabajo estable era escaso o inexistente para las mujeres, por lo que la mano de obra requerida era muy abundante y su coste bastante inferior a las cantidades - ya modestas de por sí- pagadas en Onil y poblaciones adyacentes. Las industrias muñequeras de la Foia encontraron así, a un coste similar e incluso algo inferior al que pagaban en su zona por el mismo trabajo, toda la mano de obra que necesitaron; los repartidores, cobrando una comisión de la empresa por su labor o realizando el negocio por cuenta propia, consiguieron, con uno o dos viajes semanales y el posterior reparto en su zona, unos ingresos que alcanzaban a pagar todos los gastos necesarios (entonces, sólo gasolina, vehículo y poco más) y conseguir unos beneficios suficientes; las mujeres, sin otra alternativa más rentable, realizaban un trabajo mal pagado pero compatible con otras actividades. Cuando trató de normalizarse más eficazmente el control de la actividad económica en España (mediante la implantación de impuestos como el IVA y el IAE), la solución fue relativamente sencilla, pues el repartidor se declaró trabajador autónomo y, en teoría, pasaba a ser la persona que realizaba el trabajo por sí solo; el pago de los impuestos suponía un aumento de sus gastos por lo que, incapaz de trasladarlo a unas empresas que contaban con varios distribuidores cada una de ellas, acabó repercutiéndolo en las mujeres que realizaban el trabajo. Así se siguió funcionando con relativa eficacia, mientras el trabajo se mantuviese estable y pudiese disponerse de él durante muchos meses del año.

Esta forma de externalización de la confección de vestidos para muñecas llevó a que estas labores no sólo ocupasen a algunos centenares de mujeres en la Foia y algún pueblo próximo, sino también a muchos centenares en zonas rurales de otras provincias (seguramente, millares en los momentos de mayor extensión del fenómeno). Los repartidores distribuían semanalmente su mercancía en uno o más pueblos, según los casos, distribuyendo cortes de una sola fábrica o de varias, teniendo o no la exclusividad del reparto de una firma en su zona de trabajo. A grandes rasgos, el área de reparto coincide bastante con las provincias de las que procede la mayoría de la inmigración llegada en los años sesenta y setenta a la Foia de Castalla: Albacete, Ciudad Real, Toledo, Cuenca, Murcia, Almería, Granada y Jaén; poblaciones como Tomelloso, Villacañas, Villarrobledo, Hellín, Caudete, Chirivel, Oria o Cúllar, bien en su núcleo urbano o - con mayor intensidad- en sus partidas rurales, son algunas de las principales zonas de destino de los cortes a confeccionar.

Gracias a las entrevistas mantenidas es posible describir suficientemente este trabajo. Se trata de una actividad de temporada, que en los mejores años se extendía desde los 
meses de marzo a diciembre pero que ha venido recortándose hasta reducirse básicamente al período de agosto a noviembre, salvo excepciones o pequeñas partidas. El repartidor debe disponer de furgoneta de cabida suficiente para rentabilizar los viajes y tiene que asegurarse un número relativamente amplio de mujeres dispuestas a coser y una fábrica suministradora estable o, en su defecto, varias capaces de proporcionar pedidos con cierta regularidad. Con el paso de los años fueron surgiendo también en algunas poblaciones pequeños talleres, a veces con tecnología bastante precaria según testimonios recogidos, que a menudo trataban de combinar el trabajo estable con el recurso al reparto domiciliario y la precariedad laboral. Los repartidores recogen los cortes en bolsas que, por lo general, incluían entre 40 y 144 vestidos, según tamaño de los modelos y forma de organización de la propia empresa; en las empresas grandes, aquellas que contratan la confección con varios talleres o repartidores, suelen asignarles un día semanal para entregar el trabajo finalizado y recoger las nuevas tareas, por lo que muchos deben estar en la fábricas a primera hora; al regresar, distribuían las bolsas de acuerdo con las posibilidades de trabajo de cada una de las mujeres (normalmente, mayor en aquellas con menores responsabilidades familiares) y la dificultad de la tarea, aunque en este caso trataban de hacerlo con una cierta ecuanimidad.

La práctica totalidad de quienes se dedican a estas tareas, tanto en los talleres como en el trabajo domiciliario, son mujeres; una entrevistada llegó a reírse cuando se le preguntó si había hombres dedicándose a estos menesteres, aunque a algunas les ayudan sus familiares preparándoles el trabajo. El tipo de mujer que se dedica a la confección es muy variado, con edades comprendidas entre los 20 y los 60 años, aunque predominan las de edades intermedias; son, por lo general, mujeres de pequeños municipios y de partidas rurales, aunque también se cose en pueblos grandes, con escaso empleo industrial femenino; algunas mujeres suelen compaginar estas tareas con trabajos agrarios como la vendimia o la recolección de la almendra y la aceituna, siendo práctica de ciertos lugares suspender el cosido mientras se realizan estas labores, muy limitadas temporalmente pero más rentables. La mayoría de entrevistados afirmaban considerar este tipo de trabajo como un simple complemento familiar, incluso algún repartidor trataba de convencernos de que era una especie de entretenimiento, especialmente entre las esposas de aquellos obreros que pasaban fuera de casa toda la semana, trabajando en la construcción; pero, si es indudable que no pasa de ser una ayuda al presupuesto familiar, lo es por ser un trabajo pésimamente pagado, incluso en los momentos de mayor demanda de cosedoras. Testimonios como el de la mujer que afirma haber cobrado hasta 22.000 pesetas semanales, hace unos pocos años, en los momentos de mayor trabajo, o el de la que afirma haber llegado a cobrar 80.000 pesetas mensuales por jornadas de diez horas diarias, en los meses de temporada alta, conviven con el de quienes sólo trabajan algunas horas semanales y no llegan a percibir ni 5.000 pesetas; lo más grave es que estas afirmaciones fueron realizadas en el verano de 1997, un año de fuerte incremento de la producción y, además, quejándose siempre que ya no se alcanzaban esas cifras: «ahora debo trabajar el doble para sacar lo mismo», «hace quince años estaba mucho mejor pagado», son afirmaciones usuales entre las mujeres. Algunos antiguos repartidores habían dejado ya de distribuir cortes porque afirmaban que no les era rentable dedicarse a ello; además, contaban anécdotas de desaprensivos que habían dejado sin cobrar a algunas mujeres. Con ingresos tan menguados resulta evidente que la alternativa de regularizar la situación de las mujeres es a todas luces inviable, porque los gastos significarían casi siempre cantidades superiores a los ingresos, o reducirían los ya míseros ingresos a una situación casi absurda; se trata de un trabajo marginal que debe tender a desaparecer por sí mismo y que, en caso de intentar controlarse, sólo se conseguiría eliminarlo más rápidamente. 
Algunas grandes empresas ya intentaron, a su manera, limitar los abusos más flagrantes. Un informante declaraba que, ya a principios de los ochenta, en la empresa para la que trabajaba a comisión retiraron el suministro a un repartidor que pagaba precios excepcionalmente bajos; en otra gran empresa hoy alejada de la fabricación de muñecas se afirmó que dejaron de trabajar con un distribuidor en la zona de Benilloba y otros pueblos rurales de la montaña alicantina porque pagaba cantidades inferiores a las 100 pesetas por hora trabajada a finales de los años ochenta. Aunque normalmente las empresas suelen despreocuparse de lo que ocurre más allá del trabajo satisfactoriamente realizado y con factura legalizada, algunos directivos son conscientes de que se trata de uno de los trabajos subcontratados sobre bases más inestables; saben que la confección de vestidos para muñeca difícilmente puede pagar precios similares a los de las empresas de confección para grandes cadenas comerciales o para el ejército; saben también que otras actividades irregulares, como algunas vinculadas al aparado de calzado, están mejor remuneradas, que en algunas zonas rurales comienzan a existir alternativas laborales mucho más dignas y que una regularización de esta mano de obra domiciliaria significaría un encarecimiento insostenible del producto, en parte por la competencia externa y en parte por la baja productividad. Además, las mayores exigencias de calidad del producto obligan a un control de calidad exhaustivo en el interior de la propia empresa, con el consiguiente incremento de costes. Lógicamente, algunas empresas han buscado alternativas sustitutorias.

Una de ellas ha sido la creación de talleres auxiliares de confección para muñeca. No se trata de los descritos anteriormente, más o menos entroncados con la economía marginal, sino de empresas modernas, tecnificadas, situadas en la propia comarca o cerca de ella, dedicadas también al corte industrializado de las piezas, que trabajan con calidad notable aunque a precios relativamente elevados; hoy constituyen ya una alternativa posible para la producción de mayor calidad pero a medio plazo podrían ampliar sus servicios a gamas inferiores.

Otra alternativa consiste en la importación de vestidos para muñecas procedentes de Extremo Oriente, de China principalmente. Fueron las grandes empresas las que iniciaron esta práctica. En un primer momento, adquirieron contenedores completos llenos de vestidos para muñeca y la experiencia no puede considerarse excesivamente satisfactoria; algunos directivos de estas marcas afirman que la calidad recibida no fue la deseada e incluso que aparecieron ratas o pulgas en algún envío; otros, por el contrario, salvados los problemas iniciales, continúan recibiendo este tipo de mercancía. En «Feber», que ya no fabrica muñecas, se nos informó que antes de producirse la suspensión de pagos se intentó entrar en contacto con empresas chinas, pero que se encontraron con problemas muy diversos: falta de calidad, necesidad de una planificación exhaustiva de la propia producción, carta de crédito y asumir el coste de fletes y gastos arancelarios. A nuestro juicio es «Famosa», la mayor empresa del sector, quien ha racionalizado más profundamente esta importación, mediante la creación de «Famosa Internacional» que, desde Hong Kong, establece acuerdos estables con empresas chinas, controlando la calidad del trabajo realizado en aquellas factorías, que ya no se centra sólo en la confección de vestidos sino en el conjunto del producto muñequero; la rentabilidad, que puede llegar a ser muy elevada porque se trata de empresas con tecnología suficiente, depende en gran medida de la paridad peseta/dólar.

\section{Conclusión}

La industria juguetera, que durante los últimos años ha aumentado su producción a pesar del fuerte descenso del empleo directo, ha incrementado la externalización de mu- 
chos de sus procesos productivos. Hoy existen muchos más talleres e industrias auxiliares en la Foia de Castalla que hace una década, pero, lejos de volcarse casi exclusivamente en el trabajo vinculado a la industria juguetera, tratan de abrirse paso en otros muchos sectores industriales, tratando de superar la estacionalidad que la actividad juguetera comporta.

Además de subcontratar procesos industriales a otras industrias, las empresas jugueteras constituyen un buen cliente de una gran variedad de proveedores y de empresas de servicios a las industrias. Cataluña sigue siendo la principal suministradora de material plástico, a través de multinacionales allí establecidas; también envía buen número de productos textiles, aunque otros muchos proceden de la propia Comunidad Valenciana; la maquinaria y las baterías y motores para vehículos infantiles son importados, mayoritariamente; algunos productos muy específicos, como los ojos y el pelo para muñecas o las adhesivas, han originado industrias especializadas en la propia comarca.

En cuanto a los servicios más imprescindibles, el transporte, el diseño y el control de la comercialización continúan estando muy vinculados a la propia zona; el asesoramiento fiscal y laboral también se contrata con empresas de la comarca u otras ciudades de la propia provincia; sólo la publicidad televisiva está en manos de agencias radicadas en grandes ciudades.

Aumenta la descentralización productiva, amparada por una mayor racionalización y por el desarrollo y diversificación del tejido industrial de la Foia. Las empresas jugueteras tratan de asegurar la disponibilidad de estructuras productivas externas, estabilizando sólidamente la relación con talleres de la zona, especialmente con los de matricería e inyección de plástico, aunque aumentan las pequeñas industrias dedicadas a montaje, confección, pintura y embalaje.

El montaje sigue realizándose básicamente en la zona, aunque cada vez menos en el interior de las empresas jugueteras; también se reduce el recurso al trabajo domiciliario; aumentan los talleres especializados, aunque no siempre totalmente regularizados.

La confección para muñecas constituye una actividad excepcional que desde antiguo está realizada fuera de las fábricas. Hoy sigue en manos de productores (más bien distribuidores) autónomos, recientes talleres de cosido o importaciones de Extremo Oriente. La actividad tradicional, muy mal pagada, sigue siendo desempeñada por mujeres de zonas rurales de las provincias de Andalucía Oriental, Castilla-La Mancha, Murcia y el propio Alicante. Resulta muy difícil su modernización; intentar regularizarla rápida y estrictamente significaría su desaparición, sustituida por importaciones masivas.

\section{Bibliografía}

Asociación Española de Fabricantes de Juguetes (AEFJ): Estrategias para el 2000. Tendencias futuras del sector juguetero español, Valencia, enero de 1995.

KPMG Peat Marwick: Fabricación de juegos y juguetes (CNAE, 494), Cámaras de Comercio Industria y Navegación de España, noviembre de 1992.

ROLAND BERGER \& PARTNER GMBH: Actualización de la Base de Datos del Sector Juguetero a 31 de diciembre de 1995, Madrid, julio de 1996, $126 \mathrm{pp}$.

SÁEZ CALA, Antonia y otros: La dinámica de los sistemas productivos locales. El caso de la industria del juguete en la Foia de Castalla, Universidad Autónoma de Madrid, noviembre de 1997, 153 pp.

VALERO ESCANDELL, José Ramón: «La industria juguetera de la Foia de Castalla (1984-1996)», Investigaciones Geográficas, ${ }^{\circ}$ 19, Instituto Universitario de Geografía, Universidad de Alicante, Enero-Junio 1998, pp. 67-84. 
